\title{
Prohibition of Riba and Gharar: A signaling and screening explanation?
}

Nathan Berg and Jeong-Yoo Kim

Address for correspondence:

Associate Professor Nathan Berg Department of Economics University of Otago PO Box 56 Dunedin NEW ZEALAND

Email: nathan.berg@otago.ac.nz Telephone: 6434798648 


\title{
Prohibition of Riba and Gharar: A signaling and screening explanation?
}

\author{
Nathan Berg* and Jeong-Yoo Kim ${ }^{\dagger}$
}

\begin{abstract}
The emergence of Islamic Banks (IBs) with Sharia boards that restrict the set of permissible products and enforce prohibition of riba and gharar raises basic questions of how IB clients benefit by choosing financial services from a restricted menu of possibly higher-cost cash flows. Norms that restrict choice sets or impose otherwise harsh requirements would seem to act as a potential barrier to religious identification by raising costs for IB clients. Contrary to this intuition, a theoretical model demonstrates that premium financing costs and substantial restrictions on the set of financing options considered to be Sharia-compliant provide signaling technology that benefit IB clients who are highly pious. By revealing what would otherwise remain private information about one's intensity of religious piety, the signaling technology then provides a screening service, enabling high-piety types to separate and concentrate their social and commercial interaction with others who are similarly pious. Iannaccone (1992) demonstrates a rationale for harsh norms as a mechanism for reducing free-riding in the supply of club goods. In contrast, the model in this paper shows that piety can be signaled by the act of choosing to become an IB client and bearing the costs of restricted choice sets and premium pricing for financial products. This provides a new rationalization for prohibition of riba and gharar as a stable institution. Signaling piety is especially valuable in environments where piety is uncertain and otherwise difficult for others to observe. The model predicts that IBs' Sharia-compliance criteria will tend to be stricter and IB premiums larger in places where the proportion of highly pious Muslims is small.
\end{abstract}

Key Words: Islamic, bank, norms, piety, devout, loyalty, screening, signaling JEL Classification Code: D72

${ }^{*}$ Corresponding Author: Associate Professor, Department of Economics, University of Otago, PO Box 56, Dunedin 9054, New Zealand, +64-3-479-9648, nathan.berg@otago.ac.nz

$\dagger$ Department of Economics, Kyung Hee University, Hoegi-dong, Dongdaemun-ku, Seoul 130-701, Korea, +82-2-961-0986, jyookim@khu.ac.kr 


\section{Introduction}

Today, more than 700 Islamic Banks (IBs), in addition to many conventional or non-Islamic banks, offer Islamic financial services in more than 85 countries across the Middle East, Europe, the U.S., the Far East, and Southeast Asia, with over $\$ 1.2$ trillion assets under management (Abedifar, Molyneux and Tarazi, 2012, and empirical sources cited therein; Beck, Demirgüç-Kunt and Merrouche, 2013). This paper introduces a model in which IBs charge a substantial premium over conventional financial institutions for identical cash flows as an equilibrium outcome. Although lower-priced conventional financial services could serve as a perfect substitute were it not for benefits that pious individuals experience from conducting business with others who are similarly pious, the model shows that IB customers or clients rationally choose to pay a substantial premium for IB financing, because doing so provides a technology for signaling their true intensity of religious piety. In turn, Muslim communities that wish to (depending on their underlying piety types) can use this costly signaling technology to screen for piety and achieve a separating equilibrium that enables high-piety types to coordinate and thereby achieve surplus generated through interaction with other high-piety types.

High- and low-piety types are assumed to have identical valuations of the financial products that IBs offer and differ only in the value they place on beliefs about the piety types of others with whom they associate. The benefits that high-piety types receive from doing business in an environment where most others are similarly pious is hypothesized to take the form of reduced transactions costs and a rich array of other social benefits that the model takes as exogenously given. The novel point that the model attempts to describe is that social benefits experienced by the highly pious can rationalize premium IB pricing and the separating equilibrium it generates. This mechanism rationalizing the decision among the highly pious to pay more than they would need to for financing because the signaling technology generates indirect benefits - even in the absence of any intrinsic financial advantages that IB services provide - is proposed as a new, although of course partial, explanation for the rapid growth in Islamic banking and finance in recent years (as much as 15 to 20 percent in some years, according to Haque, Jamil and Ahmad, 2007; Kahn, 2010). The real-world emergence and growth of IBs is, no doubt, complex and therefore likely to require multiple 
explanations. The signaling and screening mechanism proposed in this paper is intended to complement alternative mechanisms incentivizing some Muslims to become IB clients as described below.

According to El-Gamal (2007a), "Islamic finance is first and foremost about religious identity." Prominent among the religious tenets that distinguish the contemporary Islamic finance industry from its non-Islamic or conventional finance industry counterpart is the prohibition of riba. El-Gamal (2006) emphasizes that riba has no precise translation in English, criticizing those who misinterpret it simply as excessive or usurious payment of interest, or as motivated by a generic moral teaching to be kind and avoid exploiting those who are weak. ${ }^{1}$ El-Gamal $(2006,2007 b)$ argues instead that prohibition of riba should be interpreted as an institution for facilitating improvements in both economic efficiency and social justice, which are easily recognizable to students of economic theory. For example, requiring contracts to clearly specify fluctuating equity stakes (i.e., marking asset values to current market prices), without using conventional credit and interest-rate financing, may help avoid counter-party risk and save costs of contract enforcement in the event of bankruptcy. Similarly, prohibition of riba can be interpreted as incentivizing myopic decision makers to use mutually owned profit/loss sharing as a commitment device that helps avoid temptation and leads to greater accumulations of capital, anticipating by centuries the work in behavioral economics on dynamic inconsistency. ${ }^{2}$ At the same time, El-Gamal (2008) also expresses concern that pious Muslims who choose to become clients of IBs may face excessive financing costs. ${ }^{3}$

\footnotetext{
${ }^{1}$ Not all riba is interest, as illustrated by discussions of riba al-nasa versus riba al-fadl in Gamal (2001, 2003). Conversely, there are transactions that closely resemble interest payments by providing explicit compensation for the time value of money that are nevertheless, in the eyes of authoritative voices on Islamic jurisprudence, not considered riba. The time value of money is clearly acknowledged and not universally proscribed in the inspired texts on which Islamic jurisprudence is based.

2 Regarding the stability and credit risk of IBs relative to non-IBs, Baele, Farooq and Ongena (2012) report that hazard rates on IB loans are, in some settings, smaller than hazard rates on non-IB loans, while Abedifar, Molyneux and Tarazi (2012), and Beck, Demirgüç-Kunt and Merrouche (2013) find few significant differences between IB versus non-IB financial institutions.

3 El-Gamal (2002) analyzes trade-offs between equity (or the production of social responsibility) and financial efficiency, emphasizing that Islamic jurists who advocate for stricter limits on Sharia-compliant financial instruments (that, given current financial technology, would appear to be less efficient) actually
} 
This paper undertakes to complement previous work explicating the benefits and costs of prohibition of riba and gharar by proposing a simple model in which higher costs charged by an IB endure as a stable institution, precisely because the premiums that IB clients must pay provide signaling technology that enables IB clients to reveal otherwise difficult-to-observe information. Costly signaling achieved by restricting oneself to the Sharia-compliant financial services provided by IBs include both direct and indirect costs: the sum of premium financing fees (if any) charged by IBs for securities with identical cash flows and the opportunity cost of forgoing financial products not included in the restricted set of financial products offered by IBs. The model described in the next section shows that excess financing costs can be optimally chosen by the institutional designer (in this case, the IB and the Sharia board it employs) as a harsh norm that generates a separating signaling equilibrium. One novel result is that IB clients wanting to signal their high-piety type will optimally choose to pay the premium associated with choosing to be an IB client even when they receive no intrinsic benefit other than the opportunity to be publically acknowledged as a high-piety type (i.e., devout or loyal).

Social norms that reinforce religious identity typically specify rules for how group members should behave. Although not necessarily compulsory, failure to comply with religious norms may lead to both material and non-financial penalties imposed upon those who are not publically recognized as pious. What advantage do group norms that constrain individual action provide to social groups? ${ }^{4}$ Evolutionary game theory provides numerous hypotheses have in mind a longer-term Islamic finance technology set which is anticipated to improve efficiency beyond what is feasible today. Although this does not appear to have been analyzed using the standard finance textbook approach of representing the financial technology space as a universe of risk-return pairs, we can translate El-Gamal's long-term/short-term distinction as follows. If $\Omega$ represents the universe of all pairs of risk and expected return provided by non-Islamic financial technology and $\Omega_{S}$ represents the strict subset of Sharia-compliant financial instruments, then the short-term relationship of subset and superset, $\Omega_{S} \subset \Omega$ is not anticipated to hold in the future, insofar as future IB technology develops (i.e., $\Omega_{S}$ expands) to exceed the performance of the envelope, or frontier, representing the "bullet" of risk-return space in conventional finance theory. The vertical gap between expected return using non-IB financing and expected return using the nearest Sharia-compliant technology along any vertical line in risk-return space is one interpretation of the continuum of premiums over non-IB financing costs that agents in the model presented in the next section face when deciding to become an IB customer or client.

${ }^{4}$ Sociologists' definitions of "social group" usually require interaction and rules constraining action, which 
addressing this question. El-Gamal (1998) provides a model with three types of agents in which "weak" IBs, which are hybrids adhering to Islamic norms when dealing with their own types but acting as conventional banks when dealing with non-Muslims, are necessary for the survival of strictly pious agents, consistent with the signaling motive in this paper. Aziz (1967) describes how small, seemingly irrelevant features of religious groups' headgear are interpreted as vitally important markers of group identity in India: Hindus in India belonging to groups with particular religious convictions wear headgear known as the "Gandhi cap," while similarly positioned Muslims wear the "Jinnah cap." Markers of group membership frequently endure based on subtle interpretations of what would appear to outsiders as small, irrelevant detail (e.g., whether one's hat reveals any animal fur) that are nevertheless existentially vital to group members.

Benefit-cost calculus implies, all else equal, that higher financing costs for identical financial securities, which do not provide any additional flows of intrinsic payoffs, would never be chosen voluntarily. By taking into account the benefits that pious individuals (and their religious group leaders) receive from associating and conducting business with those who are similarly pious, this paper proposes a rational-choice explanation for the persistence and growth of an IB that offers identical (ex ante) cash flows at a significantly higher cost. These higher costs are needed to induce the separating equilibrium that reveals private information

sharpens the definitional requirements of a social group in ways that go beyond shared characteristics such as ethnicity or one's ancestral religious affiliation. According to such definitions, social groups are defined by distinct patterns of social interaction and specific actions that set group members apart from mere aggregations of people who happen to have the same gender, income group or ancestral religious affiliation. Drawing on the psychological theory of cognitive dissonance, Aronson and Mills (1959) provide an interesting rationale for why members of social groups can be regularly observed to choose to endure unpleasant experiences. They suggest that unpleasant initiation ceremonies can prepare group members for future disappointments, which are inevitable in any event, but also serve to strengthen the group and its members' identification with it. Their theory rests on a psychological mechanism that seeks to avoid cognitive dissonance, cultivating a form of sunk-cost sensitivity that works in favor of the group's survival, especially when individual group members face unexpected negative events or disappointments associated with their group. As an example, painful initiation ceremonies may lead group members to reason: "If I went through so much to become a member of this group, then it must be beneficial for me to continue identifying with the group given all that I sacrificed or endured, in spite of the flaws I am noticing now." The present paper draws on a companion paper of ours focused on the interpretation of distance as a more general form of costly social norm. 
regarding piety that pious individuals want to reveal. ${ }^{5}$ The model is a thought experiment demonstrating that premium IB financing, consisting of a restricted (i.e., strict) subset of risk-return attributes (or other stochastic characteristics generally relevant to clients of the financial services industry), can serve as a signaling technology which provides real, economic benefits in the form of coordination among the pious - even when the financial services offered by IBs deliver no intrinsic (i.e., religious or non-pecuniary) benefit.

The assumption that IBs provide only the benefit of coordination among the pious through signaling serves as a modelling device to focus on this mechanism while abstracting from other valid motives for clients to choose IBs. We enthusiastically acknowledge the vision of improved alignment of incentives between banks and their clients, in addition to the real value of improved social responsibility, that have drawn economists' and jurists' interest in the analysis of IBs. Abedifar, Molyneux and Tarazi (2012) argue that pious Muslims who hold deposits at IBs may enjoy reduced credit risk in their banks because the religiosity among the banks' borrowers decreases rates of default (and withdrawal risk) among clients. Baele, Farooq and Ongena (2012) report evidence of reduced default rates consistent with a model (presented in their Appendix E) in which religiosity generates lower default rates and improved stability among IBs relative to non-Islamic banks. And El Gamal (2002) describes Islamic jurists' vision of long-term improvements in both social equity and financial efficiency provided by IBs relative to what is currently offered along the envelope of existing financial technologies. Beck, Demirgüç-Kunt and Merrouche (2013), Kahn (2010), and other observers, however, point to a set of stylized facts surrounding existing IBs suggesting that there are few substantial differences between IBs and conventional financial institutions, at least when measured by standard metrics of business activity and financial performance. Questions raised by this body of empirical work and the theoretical investigations of El Gamal (2002) and Kahn (2010) lend at least tentative support to the abstractions in our model by suggesting that the emergence and functional differences of IBs (if any) remain open questions and therefore worthwhile targets for new theoretical explanations.

Iannaccone's (1992) seminal paper seeks to explain restrictions on individuals' choice or action sets that religious groups require for group membership. Iannaccone considers a

\footnotetext{
${ }^{5}$ In the sociology literature, similar assertions linking harsh or restrictive norms to group loyalty are well known, although they are not formalized as a game-theoretic model (Brown, 1988).
} 
trade-off between secular activities and religious activities. In contrast, the model in the present paper investigates a trade-off between intrinsic utility (derived from either secular or religious activity) and extrinsic utility that a pious individual receives from signaling his or her true type. In Iannaccone's model, religion is seen as a club good, and seemingly unproductive norms serve to reduce free-riding (i.e., inducing group members to switch from secular activities into religious activities by raising the cost of secular activities). Moreover, Iannaccone's model predicts that the cost-shifting which harsh norms generate also produces a screening effect that sorts less committed members into groups with less demanding group norms. In contrast to the motives of IB clients in this paper, there is no reputational concern in the form of benefits from signaling one's type to other group members in Iannaccone's model.

The signaling mechanism in this paper provides a new interpretation of higher financing costs relative to non-Islamic banks, which includes situations where IBs do not charge a premium for their services but IB clients nevertheless face an opportunity cost of restricting their choices to a set of Sharia-compliant IB products that do not include the client's most preferred choice from the set of all conventional products. These costs serve as a screening device whose value arises on the basis of signaling inherently heterogeneous and otherwise difficult-to-observe piety status. Describing this signaling device as generating benefits through signaling or "reputational concern" does not imply superficiality, as reputations can help coordinate economic and religious decisions while lowering transaction costs that generate important secondary intrinsic payoffs that are not included explicitly in the model. ${ }^{6}$ Empirical evidence demonstrating significantly higher rates of contract compliance among those who choose Islamic-compliant contracts over non-IB interest-based contracts provides support for the intuition that signaling, which facilitates interaction among high-piety types, can provide real economic benefits (El-Komi and Croson, 2012). The real economic benefits mentioned in El-Gamal (2006), which include contracts that are disciplined by mark-tomarket accounting, Pareto efficiency, and self-commitment devices that mitigate dynamic

\footnotetext{
${ }^{6}$ Berman (2000) explains demanding religious practices among Ultra-Orthodox Jews and so-called Islamic fundamentalists as expressing commitment to the group or community, which is similar in spirit to ideas motivating the present paper, without, however, providing a formal model of signaling to rationalize the emergence and stability of harsh norms in religious groups.
} 
inconsistency, should also be kept in mind as complementing the signaling and screening services of IBs that this paper focuses on.

The vast economics literature on social norms draws on insights from the models of Banerjee (1992) and Bikhchandani, Hirshleifer and Welch (1992). Bernheim (1994) presents a model of agents who conform to social norms, choosing to send costly signals that sacrifice intrinsic utility to achieve greater extrinsic utility. However, the extrinsic utility in Bernheim's model is identified with social status while, in this paper, extrinsic utility is the recognition of piety by other group members. Also, unlike Bernheim's framework in which the social norm is exogenously given, this paper explicitly models the IB's decision of how costly (or restrictive) its Islamic financial services should be, which represents the judgment of Sharia boards employed by IBs to decide thresholds used to designate Sharia-compliant products and/or mechanisms to cleanse profits (see El-Gamal, 2003, 2006, for discussions of the thresholds set by IBs' Sharia boards).

Kuran's (1998) analysis of dynamical issues in the emergence of group norms through reputational cascades focuses on the case of ethnic group identity. Kuran argues that ethnic norms become more demanding through a process of "ethnification" of group members (i.e., a self-reinforcing process in which group members are motivated to protect their reputations by escalating each other's ethnic-specific activity). Patel and Cartwright (2012) also consider how norms evolve, linking the rigidity of interpretations of a publically observable act of group identification to the number of observers.

Azar's (2004) original take on the frequently studied issue of group norms makes an interesting claim that, it should be pointed out, contradicts one of the predictions of our model. Azar's model implies that hard-to-follow or restrictive norms are, under a wide range of conditions, unstable and can be expected to gradually fade away over time. In contrast, the model in the present paper characterizes IBs that impose excess costs relative to non-Islamic banks as an equilibrium. Our model does make further predictions about the determinants of the size of IB premiums and conditions on belief formation that would lead to competition among IBs toward stricter versus more lenient Sharia-compliance conditions. These predictions link IB premiums and restrictiveness to potentially observable changes in IB clients' environment that have coincided with the emergence and growth of IBs. For example, internet communication and internet banking may reduce the signaling power of 
alternative means of signaling. As online choice sets available to one's neighbors and business associates expand, it may become more difficult to draw inferences about their piety from previously used signals of piety based on participation in religious services and related rites. The same goes for sharp increases in wealth and income, which adds intuitive appeal to the signaling motive, especially for well-off Muslims, for voluntarily choosing higher-cost and/or more restrictive IB financial services as signals that are costly to fake and substantially more effective at shifting others' beliefs about their piety, as more traditional signaling technologies become less persuasive.

Akerlof (1983) analyzes where loyalty comes from and those factors that affect its intensity. The IB's decision of setting restrictions that determine the costs its clients face is formally similar to "standard setting" in Akerlof's model and the law and economic literature. Brown (1973) formalizes tort law in the language of economics and discusses the socially optimal legal standard. In a similar vein, Kim (2011) considers two types of victims and proposes a liability rule that induces high types to signal their type by taking on additional precautionary measures that incur greater cost. Although there is a large body of literature on the efficiency of the negligence rule and the negligence standard (e.g., Cooter, 1985; and Edlin, 1993), we are aware of no paper aside from Kim (2011) that takes into account signaling and screening motives in standard setting.

The paper is organized as follows. Section 2 introduces the model in which an IB chooses a premium (which represents the distance in terms of additional fees and/or the restrictiveness of Sharia-compliance), and a continuum of agents seeking financing make decisions regarding whether to become IB clients. Section 3 analyzes conditions under which an agent's piety can be signaled by becoming an IB client. Section 4 considers the decision of the IB and its Sharia board in choosing an optimal premium. Section 5 considers the case of multiple IBs that compete. Section 6 presents a discussion and conclusion.

\section{Model}

This paper describes a game in which IBs set standards that determine the premium their customers or clients face (above the cost of financing using non-IB products) and seeking financial services decide whether to become IB clients as a function their own piety and 
beliefs about others' piety. The model adapts Hotelling's linear city model, where physical distance is interpreted as the restrictiveness of the set of Sharia-compliant choices that the IB offers relative to agents' outside option using conventional financial products. Therefore, the distance between agents and the IB represents additional financing costs that agents must bear to become IB clients. Agents' locations are assumed to be distributed uniformly on the unit interval, which serves to generate heterogeneity in the publically observable costs borne by individuals who must decide whether to restrict their choice sets of financial products to the menu of those approved by the IB's Sharia board. Physical movement in Hotelling's linear city model is interpreted as an agent's decision to move away from his or her exogenously given outside financing option offered by non-Islamic financial institutions and instead become an IB client. ${ }^{7}$

The model assumes that each agent faces a cost of becoming an IB client proportional to the distance travelled from his or her initial position to the "location" of the IB. The location of the IB, in turn, is the decision of the IB and its Sharia board. By choosing the IB's distance from agents' outside financing options, the IB's choice of location can be interpreted as a scalar-valued proxy that encompasses additional fees for borrowing, lower rates of return (per risk unit) for depositors, and the restrictiveness of the range of products offered, which jointly determine the premium that potential IB clients will publically incur (relative to their outside financing options from conventional banks or financial institutions).

If the IB is located at $z \in[0, \infty)$, then the cost borne by an agent at location $x$ when he or she becomes an IB client (by choosing to use its financial products) is represented by the expression $t|z-x|$, where $t>0$ translates distance into forgone payoffs and the distance norm is given by the absolute value of the difference between the IB's location $z$ and the agent's location $x$. The assumption that $z$ can take on any value in the non-negative real line while agents' initial locations are restricted to the unit interval implies that the IB may choose to locate either inside or outside the continuum where agents and their non-IB financing

\footnotetext{
${ }^{7}$ Baele, Farooq and Ongena (2012) present individual-level data on borrowing in Pakistan, indicating that a substantial number of IB clients in the real-world choose to simultaneously buy financial services from non-Islamic financial institutions. Our model abstracts from this possibility by assuming that all agents make a binary choice of IB- versus non-IB-client status. Generalizing the model so that agents can choose weighted portfolios of loan and deposit positions across both IB and non-IB institutions, and the inferences that others draw from these choices, is an issue for future research to investigate.
} 
options are located. If the IB chooses to locate outside the unit interval, then all agents face a non-zero cost premium to become an IB client. If the IB is in the unit interval, then there will exist dense subsets of the population that are IB clients but face an arbitrarily small IB premium. Therefore, a decision of the IB to locate outside the unit interval would imply that it has chosen to offer a set of products that imposes a substantial premium financing cost on all its clients, although this premium varies across agents depending on their initial position $x$.

Figure 1 illustrates one possible source of heterogeneity among agents' outside financing options based on the Markowitz "bullet" from the CAPM model in standard textbook finance. The main point of Figure 1, however, is that there are multiple interpretations of the exogenously given heterogeneity in premiums that agents face if they choose to become IB clients, in the case of the CAPM interpretation, depending on how the Sharia board chooses the gap between the boundary of set of Sharia-compliant securities and the efficient frontier of the universe of all securities (compliant or non-compliant). Many possible interpretations can be made to fit consistently with the abstraction of a continuum of "distances" in the Hotelling framework, which also appears in El Gamal (2002) with distance representing the stringency or restrictiveness of an IB's Sharia-compliance criteria. In Figure 1, we suppose that the continuum of agents' outside financing options are represented by the continuum of points along the efficient frontier of the universe of risk and expected return pairs $(\sigma, \mathrm{E}[r])$, denoted $\Omega$, corresponding to financial positions available at non-Islamic financial institutions and unrestricted by Sharia compliance. Strictly below this unrestricted efficiency frontier is a Sharia-compliant efficiency frontier offered by the IB, denoted $\Omega_{S}$. Vertical gaps between points along the efficient frontier of $\Omega$ and $\Omega_{S}$ generate a continuum of risk-adjusted costs in units of forgone expected return (holding $\sigma$ constant) that increase from left to right as a function of $\sigma$. Three agents at initial points $x_{1}, x_{2}$ and $x_{3}$ on the unit interval in the Hotelling model correspond to three different levels of desired risk exposure plotted by $\sigma$-components plotted in risk-return space in Figure 1. The parameter $t$, in this example re-scales distances in the Hotelling model into units of forgone expected risk-adjusted return.

In Figure 1 (which is only suggestive and far from exhaustive), agents' different initial positions are interpreted as different exogenously given risk preferences, or non-Islamic banks' different risk ratings of agent's financial goals. In this case, the continuum of agents' initial 
locations represents a linear re-scaling of agents' risk targets. The implication for the linearly increasing gap between upper boundaries of $\Omega$ and $\Omega_{S}$ as depicted in Figure 1 would imply that agents with the largest desired levels of $\sigma$ face the greatest premium financing costs and therefore generate the most powerful signals when choosing to become an IB client. Notice, however, that the IB could just as well choose the shape of $\Omega_{S}$ so that the vertical distances are largest for low values of $\sigma$ so that the gap between the two efficient frontiers decreases in $\sigma$. Therefore, the model imposes no assumption systematically linking distances $|z-x|$ to IB premiums relative to agents' exogenously given outside finance option. Another interpretation of heterogeneity in the Hotelling model would be different income levels in a population with identical risk and return targets, and then $t$ would re-scale units of Hotelling distance to currency units forgone when choosing to be an IB client instead of units of expected return as in Figure 1 (with all agents' positions corresponding a single gap between expected returns at the most preferred point in $\Omega$ and that of $\Omega_{S}$. The distribution of initial positions $x$ could alternatively result from different credit histories, heterogeneous availability of local banking services, or historical ties with different banking brands generating heterogeneous distances travelled in the space of brands. Although risk preferences and income would appear to be systematically linked to IB-client status in the real world, the model does not pre-suppose this link: heterogeneous risk preferences and incomes need not have anything to do with the heterogeneous premiums that agents face in the model.

Figure 1 illustrates just one possible source of individual-level heterogeneity that generates an exogenously given distribution of premiums that agents face when deciding whether to become IB clients. The IB, in turn, has only one scalar-valued decision to make $(z)$ that, for values of $z$ greater than 1 , imposes premiums on all agents in the model. Notice that if the IB chooses the boundary of $\Omega_{S}$ to intersect $\Omega$ at one or more points, this would imply a zero IB premium for an agent located at that point and would correspond to the IB choosing to locate strictly within the unit interval of the Hotelling linear city. One other point regarding the wide range of interpretations possible for the distance $|z-x|$ is that, while Figure 1 depicts a continuum of savers, depositors or investors who, all else equal, prefer to maximize expected return along every fixed-risk vertical line, distance in our model could just as well apply to borrowers who face a distribution of premium borrowing costs over non-IB credit products. 
The model assumes that agents receive no direct utility from using IB financing beyond that of the outside non-IB financing option which, as mentioned before, is normalized to zero. If intrinsic utility from being an IB client is included in the model, the qualitative results continue to hold, as an extension presented in a later section demonstrates. By abstracting from the multiplicity of motives among pious IB clients in the real world, this assumption of zero intrinsic utility derived from IB-client status focuses attention on the signaling mechanism and shows the economically interesting case of IB clients who rationally choose to pay a premium to shift others' beliefs about their piety. Agents whose initial positions are farther away from the IB are endowed with the possibility (or curse) of publically incurring a greater cost of signaling piety that generates a more persuasive signal (i.e., a signal that shifts others' beliefs about their piety closer to 1).

An agent's true but unobservable piety type $\omega$ is assumed to be binary: either high $(\omega=H)$ or low $(\omega=L), H>L$. An agent's piety type is private information that other agents, including the IB and its Sharia board, do not know and can never observe directly. What is common knowledge, however, is that the proportion of pious agents in the whole population is $\mu \in(0,1)$. It is also assumed that each agent's initial location $(x)$ is known to all agents in the model.

Agents are assumed to make inferences or generate beliefs about the piety of others by observing whether or not that person is an IB client. The observability of piety, which is the key component of the signaling mechanism analyzed in this paper, has two main components. These are the two publically observable variables that each agent is assumed to regard as common knowledge: an agent's initial location and his or her decision of whether to become an IB client. Agents update their beliefs about the distribution of all others' piety types according to Bayes' Rule. Based on an agent's observed IB status, other agents form posterior beliefs about that agent's piety type, denoted $\hat{\mu}$, which (in the context of the stylized model) completely characterize each agent's reputation.

The next step is to specify the social production function that maps an agent's true piety type $\omega$ and others' beliefs about his or her type $\hat{\mu}$ into a utility flow. The assumption is that agents receive extrinsic utility directly from their reputations as a function of their true piety type. Together, the exogenously given types and endogenous belief outcomes generate interactions with others that create real flows that are valued differently depending on each 
agent's true piety type. The model assumes that pious types value their reputations in terms of being willing to bear a higher cost to publically express piety than non-pious types. Interactions with fellow religious group members that have reputations as high-piety types generate positive utility, which may include lower transaction costs from contracting with other pious group members, the provision of aid to fellow high-piety types, benefits resulting from coordination, communication of religiously informed insights among the pious, and other channels as well. ${ }^{8}$

The benefit an individual gets from interacting with another agent is given by $b_{\omega} \hat{\mu}$, which assumes proportionality to the other agent's perceived type $\hat{\mu}$, with the rate of proportionality $b_{\omega}$ shifted down or up by one's own piety type: $\left(b_{H}>b_{L}>0\right)$. This simple functional form implies that the marginal productivity of one's reputation in the eyes of other agents depends on those other agents' piety types, capturing the idea that pious agents value other agents' piety more highly than the non-pious do, all else equal. ${ }^{9}$

Given the definitions above, the model is a three-stage game described as follows. First, the IB and its Sharia board choose the IB's location $z \in[0, \infty)$, interpreted as a choice of stringency or restrictiveness of the financial services offered by the IB which, together with the client's outside financing option as determined by his or her location, maps directly into the IB premium that an IB client faces. Second, individual agents decide whether to become IB clients. ${ }^{10}$ And third, all agents in the model make inferences about the piety types of

\footnotetext{
${ }^{8}$ Compared with religious communities such as Christian Protestants that emphasize a direct, personal relationship with God requiring few, if any, intermediaries or additional relationships with other humans required to pray and receive blessings from God, one referee suggested that the role of reputations for piety and their implications for interactions with others Muslims may be more important in Muslim communities that do not emphasize a direct, personal relationship with God in the way that Protestant Christians and other religious groups do. Insofar as reputational concern for piety plays a more important role in pious Muslim communities, then this observation would strengthen the case for the model's explanation. We note that there are many Christian banks and financial institutions that serve pious non-Muslim religious communities, although the financial services they offer may be less distinct than in the case of IBs. The final section of this paper takes up this issue of interpreting the model's relevance for the particular case of IBs as a growing and distinct institution.

${ }^{9}$ If interacting with others involves the production of a public good, for example, the functional form $b_{\omega} \hat{\mu}$ means that a pious agent (who has larger $b_{\omega}$ ) values any provision of that public good more than a less pious one values it (assuming that both exert the same level of effort in producing the public good).

10 As mentioned above, some banks and financial institutions sell both IB and non-IB products. Thus, an
} 
other agents based on others' locations (i.e., outside financing option) and their decisions to become IB clients or not.

\section{Decision of Whether to Become an IB Client}

In this section, the location of the IB, $z$, is taken as given and decisions by agents of whether to become an IB client are analyzed. Each agent's piety type is assumed to be private information. By incurring the cost of choosing to become an IB, which is observable to others, each agent has an opportunity to send a signal that shifts others' perceptions of his or her piety higher (i.e., resulting in a larger posterior belief among others that the agent is a high-piety type conditional on the agent being an IB client, and shifting lower conditional on not being an IB client).

The analysis in this section restricts attention to strategies based on a threshold rule referred to as the simple partition property (SPP): an agent of type $\omega$ chooses to become an IB client if and only if $d_{z}(x) \leq d_{\omega}$, where $d_{z}(x)=|z-x|$ is the distance travelled from the initial location $x$ to the IB located at $z$, and $d_{\omega}$ is an endogenous threshold measuring maximum willingness to travel to be an IB client (which maps 1-1 into maximum willingness to pay an IB premium in units of forgone utility) depending on one's true but unobserved piety type. Although the previous subsection introduced a simple functional form assuming that the excess financing costs of IB clients (relative to their outside financing option) is proportional to $d_{z}(x)$, the final section of this paper relaxes that assumption, showing that all the theorems which follow continue to hold using a generalized cost function assumed only to be strictly increasing in $d_{z}(x)$.

By restricting the preference structure in this way, the strategy rule of all agents in the population can be defined as a pair consisting of (population- and not individual-specific) cutoff values for low- and high-types, denoted $\left(d_{L}, d_{H}\right)$. The low-type cut-off $d_{L}$ (which depends on all low-type agents' endogenous choices and beliefs about others) measures the maximum willingness to travel among all low-piety types (proportional to maximum willingness to pay). Similarly, $d_{H}$ measures maximum willingness to travel among all high-piety types.

An equilibrium is defined as a separating equilibrium if $d_{H}>d_{L}$, because the posterior individual's choice could be alternatively interpreted as whether he or she buys an IB or non-IB product. 
rate of high-piety types conditional on being an IB client (i.e., having a reputation for, or being perceived by others as, a high-piety type) will be greater than among non-IB clients and will therefore send a meaningful signal. Although the location of the IB $(z)$ is taken as given by agents when deciding whether to become IB clients (analyzed in a later subsection), the inequality that defines separating equilibrium $\left(d_{H}>d_{L}\right)$ suggests the possibility ofwithout requiring or guaranteeing - that the IB can achieve perfect purity, or 100 percent high-piety types among its clients, by locating at any distance greater than $d_{L}$ (too far away to be worthwhile for any low-piety type) and less than $d_{H}$ (worthwhile for at least some high-piety types). ${ }^{11}$ It remains to be shown, however, how the IB will choose its location, which is analyzed subsequently.

An equilibrium is defined as a pooling equilibrium if $d_{H}=d_{L}$, because equal cut-off values measuring willingness to travel imply equal posterior probabilities of being a high-piety type conditional on IB-client status: $\hat{\mu}=\mu$ for all agents in a pooling equilibrium regardless of IB-client status. In contrast to a separating equilibrium in which an agent's reputation $(\hat{\mu})$ generally depends on (and is shifted higher toward 1 when conditioned on) IB-client status, the defining characteristic of the definition of pooling equilibrium is that no information about underlying piety types is revealed. In other words, the reputation for piety among IB clients is equal to (i.e., indistinguishable from) that of non-IB clients, implying that IBclient status conveys no information about underlying type and therefore no informational value as a signal. In a pooling equilibrium, it nevertheless remains rational for high-type agents (whose distance is less than the pooling equilibrium distance) to choose to be IB clients, because if they were to deviate from the pooling equilibrium strategy, then others would regard them as low-piety types with probability 1 (i.e., $\hat{\mu}=0$ ). This paradoxical result of a stable pooling equilibrium where IB clients pay for a premium that buys them no reputational gain, but merely serves to prevent reputational loss, is among the striking findings of the model, although one hastens to add that pooling equilibria do not necessarily exist (when society has a sufficiently small proportion of high-piety types, i.e., sufficiently small $\mu$ ), as shown below.

\footnotetext{
${ }^{11}$ Unlike standard signaling games, in this model, not all agents will choose to reveal their true type in a separating equilibrium. Some high-piety types with initial positions $x$ sufficiently far away from the IB (i.e., facing relatively large costs of becoming an IB client) may not become IB clients.
} 
It is worth emphasizing what is different based solely on the definitions of separating and pooling equilibria given above. In a separating equilibrium, the two types of agents (when located at the same $x$ ) will potentially make different decisions about becoming an IB client, depending on their willingness to pay a premium in finance costs for the extrinsic rewards of being an IB client. These different decisions among high- versus low-piety types imply a different posterior probability of being a high-piety type (referred to as the reputation $\hat{\mu}$ ), which depends on: (i) whether one is an IB client and (ii) the distance between one's initial location or outside financing option and the IB. In a pooling equilibrium, agents of both types at a particular location $x$ behave in the same way regardless of their true piety type.

In the analysis below, this paper employs weak Perfect Bayesian equilibrium (wPBE) as the main equilibrium concept, ${ }^{12}$ and universal divinity as a refined equilibrium concept whenever refinement is needed. Agents with $d_{z}(x)=d$ are sometimes denoted simply by $d$. An agent's binary decision of becoming an IB client is represented by the action $m$ (i.e., sending a "message" or signal), such that $m=1$ indicates "IB client" and $m=0$ indicates "non-IB client."

The posterior belief $\hat{\mu}$ is updated according to Bayes' Rule, conditional on the observed value of an agent's choice of $m$ and his or her distance from the IB $d_{z}(x)$. The dependence of conditional beliefs (about piety) on an agent's action $m$ and distance $d_{z}(x)$ is expressed by denoting the posterior belief as $\hat{\mu}(m, d)$. Universal divinity can be invoked at off-equilibrium action profiles where Bayes' Rule is no longer applicable. Universal divinity requires offequilibrium beliefs to place positive probability only on those types that are most likely to deviate. $^{13}$ Formally, define $D(\omega, m)=\{\hat{\mu} \mid \hat{\mu}$ makes type $\omega$ better off by sending $m$ than in equilibriun Then, for an off-equilibrium message $m$, universal divinity requires that the posterior belief assigns probability one to type $\omega^{\prime}$, if $D(\omega, m) \subset D\left(\omega^{\prime}, m\right)$.

\footnotetext{
${ }^{12}$ The wPBE concept is defined as a profile of strategies and beliefs such that (i) each type of agent makes a payoff-maximizing choice based on beliefs at each information set and (ii) the posterior beliefs must be updated according to the Bayesian rule whenever possible. Further details on the definition of wPBE are found in Mas-Colell et al. (1995).

${ }^{13}$ Although this concept was first proposed by Banks and Sobel (1987), it was redefined by Cho and Kreps (1987) whose definitions are followed in the present paper's analysis.
} 
The payoff for an agent of type $\omega$ at distance $d$ from the IB can be expressed as:

$$
u(m, d ; \omega)= \begin{cases}-t d_{z}(x)+b_{\omega} \hat{\mu}(1, d) & \text { if } m=1 \\ b_{\omega} \hat{\mu}(0, d) & \text { if } m=0 .\end{cases}
$$

\subsection{Separating Equilibria}

It is not possible to have $d_{H}<d_{L}$ in equilibrium. This follows from the utility function above and the observation that a high-piety type prefers being an IB client in equilibrium whenever a low-piety type at the same location and with the same reputation $(\hat{\mu})$ does: $b_{H}>b_{L}$ and $\hat{\mu}>0$ imply that $-t d_{z}(x)+b_{H} \hat{\mu}>-t d_{z}(x)+b_{L} \hat{\mu}>0$. If $d_{H}<d_{L}$, then the last inequality implies that the best response for an agent at distance $d \in\left(d_{H}, d_{L}\right)$ is inconsistent with $d_{H}<d_{L}$. Therefore, it must be that $d_{H}>d_{L}$ in a separating equilibrium, which implies that the reputation of an agent conditional on his or her IB client status is:

$$
\hat{\mu}(m, d)= \begin{cases}1 & \text { if } d_{z}(x) \in\left[d_{L}, d_{H}\right] \text { and the agent is an IB client }(m=1) \\ 0 & \text { if } d_{z}(x) \in\left[d_{L}, d_{H}\right] \text { and the agent is a non-IB client }(m=0) \\ \mu & \text { if } d_{z}(x) \in\left(d_{H}, \infty\right) \text { is a non-IB client, or } d_{z}(x) \in\left[0, d_{L}\right) \text { is an IB client. }\end{cases}
$$

Rationalization of equilibrium exploits the assumption that agents in this model assign the following belief whenever the signal is ambiguous: $\hat{\mu}=0$, if either $d_{z}(x) \in\left(d_{H}, \infty\right)$ and the agent is an IB client or $d_{z}(x) \in\left[0, d_{L}\right)$ and the agent is a non-IB client. ${ }^{14}$

The incentive compatibility conditions imply that, for any $d_{z}(x) \in\left[d_{L}, d_{H}\right], b_{L} \leq t d_{z}(x) \leq$ $b_{H}$. The first inequality requires that the disutility from the extra cost incurred by becoming an IB client exceeds the reputational benefit for a low-piety type $(\omega=L)$ with $d_{z}(x) \in$ $\left[d_{L}, d_{H}\right]$. The second inequality requires that the reverse is true for a high-piety type $(\omega=H)$. Let $\bar{d}=\frac{b_{H}}{t}$ and $\underline{d}=\frac{b_{L}}{t}$. Then $\bar{d}(\underline{d}$, respectively) represents the distance for the $H$ type $(L$ type) that makes the cost of becoming an IB client just equal to the extrinsic gain from having

\footnotetext{
${ }^{14}$ This pessimistic belief can be justified by a more refined equilibrium concept such as universal divinity. For example, when $d_{z}(x) \in\left[0, d_{L}\right)$ and the agent is observed to be a non-IB client $(m=0)$, a low-piety type is more likely to make such a deviation, since $D(H, 0) \subset D(L, 0)$ where $D(\omega, 0)=\left\{\hat{\mu} \mid \hat{\mu} \geq \mu-t d_{z}(x) / b_{\omega}\right\}$ is the set of posterior beliefs that imply that type $\omega$ will send signal $m=0$. This means that the signal $m=0$ is more likely to come from the low-piety type $L$ and implies that the agent at distance $d_{z}(x)$ must be type $L$. For the case that $d_{z}(x) \in\left(d_{H}, \infty\right)$, the pessimistic belief is incongruous with universal divinity unless $d_{H} \geq \bar{d} \equiv b_{H} / t$. For details, see the proof of Theorem 1, part (iii) in the Appendix.
} 
a reputation for being a high-piety type. In order for the pair of limit distances $\left(d_{L}, d_{H}\right)$ to be an equilibrium, it must be that $\left[d_{L}, d_{H}\right] \subset[\underline{d}, \bar{d}]$, in particular, $\underline{d} \leq d_{L}$. Otherwise, the incentive compatibility condition for an agent with $d \in\left(d_{L}, \underline{d}\right)$ would be violated. To see this, suppose that $d_{L}<\underline{d}$ and consider a low-piety type with $d \in\left(d_{L}, \underline{d}\right)$. This agent will choose to be a non-IB client as a result of the separating equilibrium condition. However, this agent actually prefers being an IB client, because $-t d_{z}(x)+b_{L}>0$. This is a contradiction from which it follows that $\left[d_{L}, d_{H}\right] \subset[\underline{d}, \bar{d}]$.

For all $d_{z}(x) \in\left[0, d_{L}\right)$, both types must choose to be IB clients. However, consider a low-piety type with $d_{z}(x)=\underline{d}-\epsilon$ for an arbitrarily small $\epsilon>0$. By becoming an IB client, this low-piety type who faces only a small premium over the outside option to become an IB client receives $\Delta=-t d_{z}(x)+b_{L} \mu<0 .{ }^{15}$ This implies that that the low-premium and low-piety agent prefers non-IB-client status. Therefore, no separating equilibrium is possible unless $d_{z}(x) \geq \underline{d}$ for all $x \in[0,1]$. This result is summarized in the following theorem stating there can be no separating equilibrium unless the IB is located strictly outside the unit interval. The theorem implies that the IB and the restrictions decided by its Sharia board must be sufficiently harsh to impose a substantial cost on all agents who choose IB financing over their outside financing options.

Theorem 1 (i) There is no separating equilibrium unless the IB is located outside the unit interval. In other words, a separating equilibrium is impossible if $z \in[0,1]$. Separation of the IB's location from agents implies that all potential IB clients face non-zero costs: all clients must pay an IB premium, and this premium never becomes arbitrarily small for any subpopulation as it would for an epsilon ball in the neighborhood of $z$ if the IB were to choose to locate within the unit interval. (ii)There exists a separating equilibrium if $z \in$ $\left[1+d_{L}, 1+d_{H}\right]$ for some $d_{L}$ and $d_{H}$ such that $\left[d_{L}, d_{H}\right] \subset[\underline{d}, \bar{d}]$. In this separating equilibrium, low-piety types never choose to be IB clients, and only some high-piety types choose to be $I B$ clients (i.e., those high-piety types with outside finance options satisfying $x \geq z-d_{H}$ ). (iii) The universally divine separating equilibria are characterized by $d_{H} \in[(1-\mu) \bar{d}, \bar{d}]$. (iv) The separating equilibria that can be supported for all $\mu \in(0,1)$ have the unique upper bound $d_{H}=\bar{d}$.

\footnotetext{
${ }^{15}$ The inequality follows from the observation that $\Delta=-t d_{z}(x)+b_{L} \mu=-t(\underline{d}-\epsilon)+b_{L} \mu=-t \underline{d}+t \epsilon+$ $b_{L}-b_{L}(1-\mu)=t \epsilon-b_{L}(1-\mu)<0$ for a sufficiently small $\epsilon$.
} 
The proof of Theorem 1 appears in the Appendix.

In the real world and as demonstrated by El-Gamal's writings, there is both religious and economic value in the guidelines of Islamic jurisprudence concerning investing and commerce. Theorem 1 demonstrates that, complementing any intrinsic benefits of restricting oneself to financing products offered by IBs, there is also a signaling mechanism that can result in a separating equilibrium which requires the harsh religious norm of bearing higher-thanmarket costs of financing. The result above shows that, by imposing what some would regard as unnecessary costs that bring no intrinsic benefit, the religiously motivated choice of paying higher financing costs as an IB client can be rationalized as an optimal choice that benefits highly pious individuals who receive extrinsic utility from interacting with other high-piety types. The separating equilibrium that Theorem 1 describes requires that IB financing imposes a non-trivial cost, or premium, on all its customers across the full range of the heterogeneous conditions underlying the different outside financing costs they face. This non-trivial premium corresponds to the dense set on the real line to the right of the unit interval that separates the IB's location (in the separating equilibrium) from the location of agents on the unit interval, indexed by their outside financing options. This gap separating the unit interval from the location of the IB implies non-zero IB premiums for all agents who choose to become IB clients. The IB premium serves as a screening device that accurately and publically sorts at least a fraction of high- from low-piety types, thereby satisfying the incentive compatibility constraints required for the separating equilibrium to occur.

The intuition as to why there can be no separating equilibrium if the IB is located within the unit interval is that high-piety agents who would be clustered densely in a neighborhood about the IB (i.e., those who face arbitrarily small differences between the pricing of IB versus non-IB financial products) do not receive a sufficiently large informational benefit (i.e., do not have access to a sufficiently powerful signaling technology) from choosing to be an IB client, because low- and high-piety types are pooled. In other words, insufficiently harsh IB restrictions and premiums deprive IB clients of the value of sending a meaningful signal. The value of signaling disappears when low- and high-piety types are pooled. With insufficient signaling value, even high-piety types will not choose to be IB clients. No containment of potential clients in the vicinity of the IB (i.e., within any epsilon ball of $z$ ) is 
an essential component of the separating equilibrium. The separating equilibrium provides the highly pious with a signaling technology that serves as a conduit for effectively sending information about piety types that would otherwise be difficult to observe. The signaling technology provided by premium IB pricing enables the highly pious to effectively distinguish themselves from others and facilitates screened interaction among them.

Low-piety types' status as non-IB clients contributes positively to society's ability to draw any meaningful inference about the piety of those who choose to become IB clients. Formally, if $d_{L}<z-1 \leq d_{H}$, then no low-piety types choose to become IB clients, while only a strict subset of high-piety types choose the IB. The difference in extrinsic utility gained from signaling through IB-client status makes separation possible. The universally divine equilibrium in this model does not lead to the so-called Riley outcome, which is the most efficient separating equilibrium. ${ }^{16}$ Nevertheless, the main insight from Theorem 1 is that the religious norm of IB-client status among high-piety types, which is designed to be costly, provides informational benefits by screening for piety-helping the pious distinguish themselves and thereby more easily interact with other high-piety types. ${ }^{17}$

A final point regarding the separating equilibrium in Theorem 1 is the requirement that piety types are private information. Greater uncertainty about others' piety and absence of alternative signaling mechanisms (assumed to be unavailable in the model) makes premiumpriced IB-client status more valuable as a signaling device. The model therefore predicts that restrictive (i.e., more costly) IB financial services will, all else equal, tend to flourish in environments with the fewest alternative signaling devices for signaling piety. Illustrating

\footnotetext{
${ }^{16}$ The Riley outcome is the most efficient separating equilibrium, although its application in this context is certainly open to question. The Riley outcome has two key features that distinguish it from other definitions of separating equilibria. First, in a separating equilibrium, high-piety types use a costly signal that would be unnecessary under complete information. In the Riley outcome (which is unique among universally divine equilibria), this waste is maximized, since the separation interval $\left[d_{L}, d_{H}\right]$ (proportional to waste in payoff or utility units) is the largest. This could be interpreted as the least efficient outcome in the sense that IB clients sacrifice unnecessarily large premiums for IB over non-IB financial products. However, because the separation interval is largest among all the separating equilibria, the largest amount of information about true piety types is revealed. In other words, this outcome is the most informationally productive in the sense of providing the greatest aggregate extrinsic benefit generated by interaction among high-piety types.

${ }^{17}$ It is relevant to compare this result to Hirshman's (1970) interpretation of costly tests of loyalty as being analogous to useful trade barriers described in some models of protective tariffs.
} 
how Theorem 1 might be mapped into explanations and predictions regarding the rise of the Islamic finance industry, one may consider the following albeit speculative scenario.

Consider a Muslim society with a large proportion of high-piety types that experiences a sharp increase in income levels and income inequality. With greater wealth, income and visibility of that wealth and income, one may suppose that international travel and internet access becomes available for an increasing segment of society, extending across a wider range of income levels. What would these events imply about uncertainty regarding others' piety types? And how would mechanisms previously used for signaling piety be affected?

With greater income and an increasing number of visibly well-to-do Muslims, there would be greater opportunity to use money for signaling piety. There would be greater demand among those with money for technologies that enables them to send persuasive signals for maintaining social cohesion given increased social stresses from rising inequality. With greater access to travel, online trading and a seemingly inexhaustible menu of online entertainment highly inconsistent with piety, there would be greater uncertainty about the piety of those with whom we live and interact, in commerce and culture. In such a scenario, signals of piety that were previously used may no longer provide effective screening in the transformed environment, which can be interpreted as an inward shift in the supply of effective informational supply of signaling technology. Restricting what one does with one's money could be a particularly effective new signaling device.

Greater geographic mobility and increased availability of activities inconsistent with piety would threaten the effectiveness of previously used signaling and screening technologies, which can be interpreted as a decrease in the effective supply of those technologies. Greater income and uncertainty about others' piety would, at the same time, increase demand for new signaling technology. Those factors making it more difficult and/or more valuable for the highly pious to coordinate with others who are similarly pious - when viewed as a simultaneous increase in demand and decrease in the supply of signaling and screening technologies specifically for piety - predict that the price of signaling will rise. In turn, this incentivizes innovation and the entry of new suppliers of signaling technology, consistent with the recent rise of the Islamic banking and finance industry. 


\subsection{Pooling Equilibria}

This section analyzes the possibility of a pooling equilibrium. In a pooling equilibrium, a low-piety type successfully pretends to be a high-piety type by becoming an IB client even though he or she values interacting with other high-piety types less than high-piety types do. Let $d_{p}$ represent the pooling equilibrium distance measuring the maximum distance that both low- and high-piety-type agents are willing to travel to become IB clients. It generates reputations for an individual agent at distance $d_{z}(x)$ according to the following Bayesian rule: $\hat{\mu}=\mu$ if $d_{z}(x) \in\left[0, d_{p}\right)$ and the agent becomes an IB client, or $d_{z}(x) \in\left[d_{p}, \infty\right)$ and the agent becomes a non-IB client. As in the case of separating equilibria, the most pessimistic belief $\hat{\mu}=0$ is assumed along off-equilibrium paths. ${ }^{18}$ This definition helps characterize the entire set of pooling equilibria as developed below.

The incentive compatibility conditions for both types require:

$$
-t d_{z}(x)+b_{L} \mu \geq 0, \forall d_{z}(x) \in\left[0, d_{p}\right){ }^{19}
$$

Then, it follows that any $d_{p} \in(0, \underline{d} \mu]$ can be a pooling equilibrium distance.

Theorem 2 (i) There exists a continuum of pooling equilibria with the equilibrium distance in the interval $(0, \underline{d} \mu]$. (ii) Furthermore, the universally divine equilibrium reduces the set of pooling equilibrium distances to $(\bar{d}(1-\mu), \underline{d} \mu]$.

The proof of Theorem 2 appears in the Appendix.

In a pooling equilibrium, regardless of one's piety type, an agent within distance $d_{p}$ of the IB chooses to become an IB client, and agents farther away than $d_{p}$ from the IB do not. One may wonder whether a high-piety type might be able to signal piety at farther distances (i.e., incurring greater costs). It is straightforward to show that this is not possible in a pooling equilibrium, based on the assumption that beliefs about off-equilibrium-path behavior elicit

\footnotetext{
${ }^{18}$ This belief can be justified by universal divinity, although universal divinity is not necessary and therefore not as crucial as it was in motivating the separating equilibrium in the previous subsection. Assumptions about beliefs regarding off-equilibrium paths are discussed below.

${ }^{19}$ Incentive compatibility conditions also imply that $-t d_{z}(x) \leq b_{L} \mu$ for all $d_{z}(x) \in\left[d_{p}, \infty\right)$, which is always satisfied if the incentive compatibility constraint for low-piety types is satisfied.
} 
pessimistic beliefs. Although seemingly counterintuitive, the pessimistic belief assumption for off-equilibrium paths may be reasonable by the following argument.

The $\omega=H$-type receives a greater benefit from IB-client status than an $L$-type does. When any agent with $d_{z}(x)>d_{p}$ deviates from his or her expected payoff-maximizing behavior and nevertheless chooses to become an IB client implies, under universal divinity, then others believe the deviant agent is a high-piety type. ${ }^{20}$ This would mean that the pessimistic belief $\hat{\mu}=0$ is unreasonable. The consequence of universal divinity is the implication that $\hat{\mu}=1$, which requires the following incentive compatibility constraints for agents with $d_{z}(x) \in\left[d_{p}, \infty\right)$ to hold:

$$
-t d_{z}(x)+b_{H} \leq b_{H} \mu, \forall d_{z}(x) \in\left[d_{p}, \infty\right)
$$

From (3), only equilibrium distances $d_{p} \in P \equiv(\bar{d}(1-\mu), \underline{d} \mu]$ are reasonable in the sense of satisfying the incentive compatibility constraints with pessimistic beliefs. As stated in Theorem 2 , this set may or may not exist. If $\bar{d}(1-\mu)>\underline{d} \mu$, that is, $\mu<\frac{\bar{d}}{\bar{d}-\underline{d}}$, then no pooling equilibria exist $(P=\emptyset)$. Note that $\bar{d}(1-\mu)<\underline{d} \mu<\underline{d}<\bar{d}$ if $\mu>\frac{\bar{d}}{\bar{d}-\underline{d}}$, which implies that, in pooling equilibria, both types are less likely to be IB clients than under complete information.

\section{The IB and Sharia Board's Decision}

This section analyses the institutional design of the IB's product offerings and their restrictiveness or opportunity cost, identified here (heuristically) with the location of the IB (z). It is well known that proponents of IBs emphasize social welfare (e.g., Koranic notions of justice and social equity) and corporate responsibility in the form of strict Sharia compliance. Based on these motives, we assume that the IB and its Sharia board are, at least to some extent, concerned about their clients' wellbeing and adherence to Sharia. The following assumes that the IB seeks to maximize profits subject to a piety or religious purity constraint. Since no interest rate is involved, maximizing profit (in this model) is the same as maximizing the number of customers. The constraint is that its clients are high-piety types.

\footnotetext{
${ }^{20}$ More formally, $D(L, m=1) \subset D(H, m=1)$, where $D(\omega, m=1)=\left\{\hat{\mu} \mid \hat{\mu} \geq \mu+t d_{z}(x) / b_{\omega}\right\}$. Thus, if an agent with $d_{z}(x) \geq d_{p}$ is an IB client, then that agent must be perceived as $H$ by universal divinity.
} 
The IB's objective may therefore be described as maximizing the mass of the population that chooses to become IB clients such that all clients are high-piety types.

The previous section demonstrates that subgames may have multiple equilibria. ${ }^{21}$ The analysis below focuses on the equilibrium $\left[d_{L}, d_{H}\right]=[\underline{d}, \bar{d}]$, which publically reveals the most otherwise private information. Recall that the separating equilibrium is possible only if $z \geq 1+\underline{d}$. In such a separating equilibrium, it is only high-piety types who become IB clients: an agent with $x \in(z-\bar{d}, 1]$ is an IB client only if he or she is a high-piety type.

As the IB increases $z$ from $1+\underline{d}$ to $1+\bar{d}$, some high-piety types who would have chosen IB-client status will drop out and switch to non-IB-client status. Therefore, an IB seeking to maximize the mass of high-piety types who become IB clients will choose the smallest value of $z$ that can achieve a separating equilibrium, yielding the optimal location representing restrictiveness or costliness of the IB's products: $z^{*}=1+\underline{d}$. Figure 2 illustrates this optimal choice by the IB and its Sharia board, which maximizes the mass in the unit interval (measuring the number of potential IB clients) subject to the constraint that the average piety among clients remains equal to 1 . There are points to the right of $z *$ that are separating equilibria, as shown previously. But the value $z *$ attracts the largest mass of highly pious agents by selecting the minimum distance to the right of the unit interval, $\underline{d}$. Figure 2 shows the threshold distance, $\underline{d}$, to the left of which high-piety types do not choose to become IB clients and to the right of which they do become IB clients.

Theorem 3 The solution to the problem facing an IB and its Sharia board of maximizing the mass of IB clients subject to the constraint that all clients are high-piety types is $z^{*}=1+\underline{d}$, which is the smallest distance (representing the cost the IB imposes on its clients over non-IB financing) that is strict enough to achieve a separating equilibrium.

Theorem 3 shows that the IB and its Sharia board optimally choose the least-harsh distance among the set of harsh norms represented by the set separating equilibria specified in Theorem 2. The optimally chosen premium implied by the formula for $z^{*}$ in Theorem 3 confirms

\footnotetext{
${ }^{21}$ Strictly speaking, the game following the decision of the IB and its Sharia board is not a proper subgame of the larger game in which nature moves first by choosing the distribution of piety types in the population (without making it public). However, the game can easily be transformed into an equivalent game in which the uninformed IB is the first mover and nature is the second mover. Then, the subgames described here would become proper subgames in this equivalent game.
} 
the result in Theorem 2 that, in a separating equilibrium, the IB locates outside the unit interval and additionally shows that it chooses the least costly set of restrictions that are costly enough (to its clients) to screen out low-piety types. ${ }^{22}$ According to this theorem, the IB adjusts the costliness of its products to screen out all low-piety types at the least possible cost to its clients. The constraint that the IB seeks to attract only high-piety clients requires that it sets its costs just high enough so that the reputational gain for the low-piety type with the largest willingness to pay for a reputation as a high-piety type is just equal to its cost. As a result, the IB imposes greater opportunity costs on its clients, the more that low-piety types would value having a reputation and interaction with other agents with reputations for piety. Note that the value of $\mu$ has no effect on $z^{*}$ in a separating equilibrium. Changes in $\mu$ do, however, affect the possibility of pooling equilibria, which require a sufficiently high proportion of high-piety types in the population. This dependence of the existence of the pooling equilibrium on $\mu$ suggests that harsh IB premiums may not be necessary, and less likely to be observed, when the population has a high proportion of high-piety types (i.e., for large values of $\mu$ ), which make the pooling equilibria possible.

\section{Competition Among Multiple IBs}

So far, the models above assumed that there is only a single IB. This section considers the case of multiple IBs that compete to attract clients, which follows El-Gamal (2002). Suppose there are two IBs, $A$ and $B$, and denote their equilibrium locations as $z_{A}^{*}$ and $z_{B}^{*}$, respectively. Theorem 3 remains valid in the two-IB case if the equilibrium is symmetric in the sense that $z_{A}^{*}=z_{B}^{*}=1+\underline{d}$. This symmetric equilibrium can be supported by the off-equilibrium belief that a potential client is perceived to be a low-piety type (i.e., $\hat{\mu}=0$ ) if he or she is not a client of either $A$ or $B$. First, the incentive of a high-piety type located at $x \geq z-\bar{d}$ is clear, since $d_{z}(x) \leq \bar{d} \equiv b_{H} / t$ implies that $-t d_{z}(x)+b_{H} \geq 0$. The incentive of a low-piety type is also obvious, since $d_{z}(x) \geq \underline{d}$ implies that $-t d_{z}(x)+b_{L} \leq 0$. Finally, we check the incentive of IB $A$ to change its location to $z^{\prime}=1+\underline{d}-\epsilon$ or $1+\underline{d}+\epsilon$. If we impose the off-equilibrium belief that a potential client is perceived to be a low-piety type if he or she becomes a client

\footnotetext{
${ }^{22}$ In this model, a lower value of $z$ is interpreted as representing an IB choosing looser restrictions in determining Sharia compliance.
} 
of the IB at $z=1+\underline{d}-\epsilon$, then no one will buy financial services from the deviant IB $A$, since $-t d_{z}(x)+b_{H} \geq-t\left(d_{z}(x)-\epsilon\right)$ as long as $\epsilon<\underline{d}$. It is even more obvious that $A$ has no incentive to change $z$ to $1+\underline{d}+\epsilon$, since pious IB clients can enjoy an equally good reputation at lower cost by choosing $B$ instead of $A$.

In the case of symmetric equilibrium with two IBs, high-piety types located at $x \geq z^{*}-\bar{d}$ signal by being a client of either one of the IBs, and the two high-cost IBs equally split those high-piety-type clients. If an IB adopts a more lenient Sharia-compliance policy, it may seem likely that it would benefit by attracting more clients. But this is not the case. Insofar as clients of the more lenient IB lose their reputations as high-piety types, then neither IB could adopt lenient criteria for Sharia compliance without violating their high-piety constraint, and no agents would have an incentive to seek reputational and screening benefits by becoming clients. Hence, the two IBs must maintain the strict norm that imposes minimally high premiums on their clients.

Next, the possibility of an asymmetric equilibrium is considered in which one of IBs imposes a stricter Sharia-compliance policy (i.e., imposes higher premiums) than the other. Specifically, we consider the following strategies: (i) $z_{A}^{*}<z_{B}^{*}$ where $z_{A}^{*}=1+\underline{d}$ and $z_{B}^{*}=z_{A}^{*}+\epsilon$; (ii) a high-piety type located at $x \geq z_{A}^{*}-\bar{d}+\epsilon$ chooses to be a client of $B$; (iii) a high-piety type located at $z_{A}^{*}-\bar{d} \leq x<z_{A}^{*}-\bar{d}+\epsilon$ chooses to be a client of $A$; (iv) a low-piety type deals with neither IB; and (v) clients deviating from the equilibrium path are perceived to be high-piety types only if they are clients of the more remote IB. It is easy to check the incentives of a high-piety type based on the off-the-equilibrium belief specified in (v). The idea is that high-piety types who are clients of either $A$ or $B$ cannot gain by deviating from their strategies: clients of $A$ only face higher costs by switching to $B$; and clients of $B$ lose their reputation by switching to $A$.

The incentive of IB $B$ to move slightly toward IB $A$ is so strong that the strategies above could be supported as an equilibrium outcome only under more restrictive off-the-equilibrium beliefs. The problem here is that $B$ is still farther from clients than $A$ (i.e., stricter) even if $B$ moves slightly closer to $A$. This might give $B$ an incentive to move toward $A$ under the off-the-equilibrium belief stated above in the condition on beliefs stated in (v), which would invalidate the existence of asymmetric equilibrium. If we impose the more stringent belief that a client is perceived to be a high-piety type only if he deals with a more remote 
IB - and the location of the remote IB is at least $1+\underline{d}+\epsilon$ - then a deviation of $B$ toward $A$ is unprofitable under this restrictive belief, and the asymmetric equilibrium is realized. In this asymmetric equilibrium, one IB adopts a more extreme policy than the other.

Without very demanding beliefs about others' piety when off-equilibrium actions are observed, the asymmetric equilibrium may not exist: the stricter IB has an incentive to gain additional high-piety clients by becoming more lenient and moving toward A. Under these dynamics, competition would lead all IBs with stricter Sharia-compliance criteria to become progressively more lenient and cluster in a symmetric equilibrium at $z^{*}+\underline{d}$. It is also worth noticing that the race toward leniency stops at this minimal level of stringency only if all IBs are committed to satisfying their piety constraint.

In contrast, if agents hold extremely demanding beliefs about others' piety when offequilibrium outcomes occur by inferring a zero probability of being a high-piety type when others choose a more lenient option than is expected in equilibrium (as discussed above), then competition could push in the opposite direction - toward greater stringency - until a maximally tolerable level of restrictiveness or cost was achieved. Countering the intuition that competition for new clients will necessarily lead IBs to become more lenient, the presence of demanding or pessimistic beliefs about those who make off-equilibrium moves implies the possibility of competition causing arms-race dynamics which result in stricter Shariacompliance criteria. Competition leading to stricter Sharia-compliance criteria is possible only if highly demanding reputational beliefs conditional on off-equilibrium action impose a real threat of losing one's reputation (conditional on any movement toward leniency). If people believe that others are high-piety types off the equilibrium path only when they are clients of an IB at least as restrictive as the most restrictive IB, then competition for clients may lead to increasing stringency of Sharia-compliance criteria. If an IB provides a more lenient policy, then its clients who are high-piety types will be concerned about their loss of reputation and leave for a stricter IB. In the special case of the asymmetric equilibrium as discussed above, the two IBs, $A$ and $B$, divide the high-piety-type clients, but not equally, which is consistent with El-Gamal's (2002) result of market segmentation.

Figure 3 illustrates what this asymmetric equilibrium looks like (assuming it can be rationalized by demanding off-equilibrium beliefs). The Figure shows the lenient IB $A$ located at the most lenient point that attracts only high-piety types and the more stringent IB $B$ 
located to its right, imposing stricter Sharia-compliance criteria or charging higher fees. $A$ 's clients are drawn only from a segment of length $\epsilon$ (from $z^{*}-\bar{d}$ to $z^{*}-\bar{d}+\epsilon$ ), and $B$ 's clients are drawn from the right-most subset of the unit interval (from $z^{*}-\bar{d}+\epsilon$ to 1 ). Without demanding beliefs, the equilibrium shown in Figure 3 is likely to unravel, converging toward the symmetric equilibrium with both IBs at $z^{*}=1+\underline{\mathrm{d}}$. At an asymmetric action profile, the stricter IB $(B)$ typically has an incentive to increase its mass of clients by becoming more lenient - unless its clients face losing their reputations and will choose to quit being clients if their IB becomes more lenient.

Hauswald and Marquez (2006) use a circular city model similar to Hotelling's linear city to analyze competition between banks. In their model, potential customers are distributed uniformly on a circular city and possess private (customer-specific) information about their project's quality, and the banks incur investment costs to acquire customer information. However, since the banks directly obtain the information rather than make conditional inferences based on observed actions of customers, there is no signaling. The location of a bank is not a strategic variable but rather an exogenous parameter in their model. Degryse, Laeven and Ongena (2009) consider banks competing for privately informed customers. Their focus is, however, on the organizational structure of banks and how an organizational decision (centralized versus decentralized structure) affects loan pricing. They find that customers who possess well-documented information about their projects prefer "hard" or demanding banks, while customers who possess only soft information prefer "soft" or easy banks, mainly due to differences in transportation costs. The result is, once again, a segmented market analogous to the asymmetric equilibrium described above.

\section{Conclusion}

The model demonstrates that costly IB products - whether that cost is thought of as a markup over non-IB products with identical cash flows or as the opportunity cost of choosing from a more restrictive set of Sharia-compliant products - can serve as a signaling mechanism that helps highly pious people screen high- from low-piety types. Insofar as the informational benefit of making piety types public facilitates economic coordination and religious gains, then the premiums charged by IBs and restrictiveness of its Sharia-compliance criteria may 
be interpreted as socially beneficial from the point of view of high-piety types. At the same time, the extra costs that IB clients face, both explicit and implicit, are likely to be viewed by outsiders as harmful or at least puzzling.

The model introduced in this paper assumes there is an exogenously given distribution of piety types and then undertakes to isolate the information-revelation mechanism that rationalizes the introduction of costly and seemingly irrelevant religious restrictions (in the case of securities with identical cash flows but different labels) in the domain of financial decision making. The higher cost IB services provide a signaling technology that reveals private information in a socially useful manner. The result that IB-client status can be entirely irrelevant to all agents' intrinsic payoffs and nevertheless rationalizable as a stable equilibrium based solely on the informational benefits of the screening technology that IBclient status provides is intended as a thought experiment. This focus on the signaling and screening mechanism by which IBs generate value should complement and in no way exclude other explanations based on intrinsic economic benefits that Islamic banking achieves for its clients.

Of course, the model could be usefully expanded by incorporating benefits beyond signaling that IBs provide their customers. Allowing agents to receive non-informational benefits, say $v>0$, in addition to the informational benefits demonstrated in the model above does not undermine the qualitative results presented in this paper. The generalized counterparts for Theorems 1,2 and 3 all continue to hold with the modification that $\bar{d}=\frac{v+b_{H}}{t}$ and $\underline{d}=\frac{v+b_{L}}{t}$, where $v$ is the intrinsic utility from choosing to become an IB client. Another variation of the model in this paper would be to allow for nonlinear costs as a function of distance, for example, an increasing function $c\left(d_{z}(x)\right)$. Allowing for either convex or concave and strictly increasing cost functions, the only major modification for the three theorems to hold would be that $\bar{d}=c^{-1}\left(\frac{b_{H}}{t}\right)$ and $\underline{d}=c^{-1}\left(\frac{b_{L}}{t}\right)$. Since $c^{-1}(\cdot)$ is also an increasing function, the analysis for the model and theorems carry through to this generalization.

A model that could endogenize the distribution of types might provide even greater applicability to real-world dynamics in the emergence of financial institutions across different Muslim communities. If the type distribution were stochastic in a way that allowed for individual transformations between low- and high-piety types, then the model might address the role of IBs in the emergence or decline of religious sentiment in places where IBs have been 
active. The possibility of personal transformation and the work that religious institutions, including IBs, do to induce piety-enhancing transitions (and minimize exits) among the devout is a potentially important dynamic missing from models with exogenously given piety types. It would be worthwhile to analyze extensions of the model presented in this paper, which describes endogenously chosen standards of Sharia-compliant finance as an information revelation technology based on exogenously given distributions of piety types.

Finally, one can draw some testable hypotheses from the model regarding the proportion of high-piety types, the stringency of Sharia-compliance criteria, and premiums charged by IBs. The model predicts that pooling equilibria disappear when the proportion of high-piety types, $\mu$, is small. ${ }^{23}$ This would imply that a society with a lower proportion of pious Muslims is likely to have stricter IBs.

\section{Appendix}

Proof of Theorem 1: (i) If $z \in[0,1]$, then there exists $x \in[0,1]$ such that $d_{x}(z)<d_{L}, \forall d_{L} \geq \underline{d}$ and this agent will never prefer IB client status, regardless of type. Therefore, any $\left(d_{L}, d_{H}\right)$ cannot be an equilibrium. (ii) $\left(d_{L}, d_{H}\right)$ can be an equilibrium if $d_{x}(z)>d_{L}, \forall x \in[0,1]$ i.e., $z>d_{L}+1$. Also, an agent at location $x$ will prefer becoming an IB client if $d_{x}(z)<d_{H}($ i.e., if $x>z-d_{H}$ ). Thus, a separating equilibrium exists if $1+d_{L}<z \leq 1+d_{H}$. (iii) For an individual with $d>d_{H}$ and the off-equilibrium behavior of being an IB client (i.e., sending the signal $m=1)$, we have the following: $D(L, m) \subset D(H, m)$ where $D(\omega, m)=$ $\left\{\hat{\mu} \mid \hat{\mu} \geq \mu+t d_{z}(x) / b_{\omega}\right\}$. This implies that $\hat{\mu}=1$. Then, for $d>d_{H}$, IC conditions imply that $b_{\omega} \mu \geq-t d_{z}(x)+b_{\omega}$ for $\omega=L, H$, i.e., $d_{H} \geq \bar{d}(1-\mu)$. This completes the proof. (iv) This is obvious.

Proof of Theorem 2: (i) If $d_{z}(x) \leq \underline{d} \mu$, this individual will prefer IB client status since the utility of doing so $\left(-t d_{z}(x)+b_{\omega} \mu\right)$ exceeds the utility of non-IB-client status (which is 0 ),

\footnotetext{
23 The proportion $\mu$ has no effect on stringency in the separating equilibria, as is typical of most signaling games including Spence's job market signaling. It is typical of signaling models that there is a discontinuity in the separating equilibrium set at $\mu=0$. As long as $\mu>0$, costly signaling can occur, which easily covers the range of relevant societies and communities we have in mind (i.e., with strictly positive proportions of pious Muslims in the IB context). See, for example, van Damme (1987).
} 
for all $\omega=L, H$. On the other hand, an agent with $d_{z}(x)>\underline{d} \mu$ will prefer IB client status and receiving $b_{\omega} \mu$, since choosing IB client status only incurs the cost $t d_{z}(x)$. (ii) Universal divinity requires $\hat{\mu}=1$ to be the only reasonable belief given the off-equilibrium signal of IB client status. Consequently, no high-piety type will deviate if $-t d_{z}(x)+b_{H} \leq b_{H} \mu$, or equivalently, $d \geq \bar{d}(1-\mu)$. Thus, if $\bar{d}(1-\mu)<\underline{d} \mu$, then no low-piety type with $d_{z}(x) \geq d_{p}$ will deviate, and this is the case for all $d_{p} \in(\bar{d}(1-\mu), \underline{d} \mu]$.

\section{References}

[1] Abedifar, P., P. Molyneux and A. Tarazi, 2012, Risk and Stability in Islamic Banking, Review of Finance, forthcoming

[2] Akerlof, G., 1983, Loyalty Filters, American Economic Review 73, 54-63 749-75

[3] Aronson, E. and J. Mills, 1959, The Effect of Severity of Initiation on Liking for a Group, Journal of Abnormal and Social Psychology 59, 177-81

[4] Azar, O. H., 2004, What Sustains Social Norms and How They Evolve? The Case of Tipping, Journal of Economic Behavior and Organization 54, 49-64

[5] Aziz, K. K., 1967, The Making of Pakistan: A Study in Nationalism. London, Chatto \& Windus

[6] Baele, L., M. Farooq and S. Ongena, 2012, Of Religion and Redemption: Evidence from Default on Islamic Loans, Mimeo, CentER - Tilburg University

[7] Banerjee, A., 1992, A Simple Model of Herd Behavior, Quarterly Journal of Economics $107,797-817$

[8] Banks, J. and J. Sobel, 1987, Equilibrium Selection in Signaling Games, Econometrica $55,647-661$

[9] Beck, T., A. Demirgüç-Kunt and O. Merrouche, 2013, Islamic vs. Conventional Banking: Business Model, Efficiency and Stability, Journal of Banking and Finance 37, 433-447 
[10] Berman, E., 2000, Sect, Subsidy, and Sacrifice: An Economist's View of Ultra-Orthodox Jews, Quarterly Journal of Economics 115, 905-953

[11] Bernheim, D., 1994, A Theory of Conformity, Journal of Political Economy 102, 841-77

[12] Bikhchandani, S., D. Hirshleifer and I. Welch, 1992, A Theory of Fads, Fashion, Custom, and Cultural Change as Informational Cascades, Journal of Political Economy 100, 9921026

[13] Brown, J., 1973, Toward an Economic Theory of Liability, Journal of Legal Studies 2, 323-349

[14] Brown, R., 1988, Group Processes, New York: Basic Blackwell

[15] Cho, I. and D. Kreps, 1987, More Signaling Games and Stable Equilibrium, Quarterly Journal of Economics 102, 179-221

[16] Cooter, R., 1985, Unity in Torts, Contracts, and Property: The Model of Precaution, California Law Review 73, 1-51

[17] Degryse, H., L. Laeven and S. Ongena, 2009, The Impact of Organizational Structure and Lending Technology on Banking Competition, Review of Finance 13, 225-259

[18] Edlin, A., 1994, Efficient Standards of Due Care: Should Courts Find More Parties Negligent under Comparative Negligence?, International Review of Law and Economics $14,21-34$

[19] El-Gamal, M., 1998, The Survival of Islamic Banking: A Micro-Evolutionary Perspective, Islamic Economic Studies 5(1,2), 1-22.

[20] El-Gamal, M., 2001, An Economic Explication of the Prohibition of Gharar in Classical Islamic Jurisprudence, Islamic Economic Studies 8(2), 29-58.

[21] El-Gamal, M., 2002, The Economics of 21st Century Islamic Jurisprudence, Proceedings of the Fourth Harvard University Forum on Islamic Finance, Cambridge: Center for Middle Eastern Studies, Harvard University, 7-12. 
[22] El-Gamal, M., 2003, Interest and the Paradox of Contemporary Islamic Law and Finance, Fordham International Law Journal 27(1), 108-149.

[23] El-Gamal, M., 2006, Islamic Finance: Law, Economics and Practice, NY: Cambridge University Press.

[24] El-Gamal, M., 2007a, Opinion: Mahmoud El-Gamal: Incoherent Pietism and Sharia arbitrage, Financial Times, May 23, 2007.

[25] El-Gamal, M., 2007b, Mutuality as an Antidote to Rent-Seeking Shari? Arbitrage in Islamic Finance, Thunderbird International Business Review 49(2), 187-202.

[26] El-Komi, M. and Croson, R., 2012, Experiments in Islamic Microfinance, Journal of Economic Behavior and Organization.

[27] Haque A., O. Jamil and Z. Ahmad, 2007, Islamic Banking: Customer perception and its prospect on bank product selection towards Malaysian customer perspectives, presented at the Fifth International Islamic Finance Conference, 3-4th September, Kuala Lumpur.

[28] Hauswald, R. and R. Marquez, 2006, Competition and Strategic Information Acquisition in Credit Markets, Review of Financial Studies 19, 967-1000

[29] Hirschman, A. O., 1970, Exit, Voice and Loyalty, Cambridge: Harvard University Press

[30] Hirshleifer, D. and E. Rasmusen, 1989, Cooperation in a Repeated Prisoners' Dilemma with Ostracism, Journal of Economic Behavior and Organization 12, 87-106

[31] Iannaccone, L., 1992, Sacrifice and Stigma: Reducing Free-riding in Cults, Communes, and Other Collectives, Journal of Political Economy 100, 271-291

[32] Kahn, F., 2010, How ?slamic' is Islamic Banking?, Journal of Economic Behavior and Organization 76, 805-820

[33] Kim, J.-Y., 2011, Compensating for Unforeseeable Damages in Torts, Journal of Economics 104, 265-280 
[34] Kuran, T., 1998, Ethnic Norms and Their Transformation through Reputational Cascades, Journal of Legal Studies 27, 623-659

[35] Mas-Colell, A., M. Whinston and J. Green, 1995, Microeconomic Theory. New York: Oxford University Press

[36] Patel, A. and E. Cartwright, 2012, Naïve Beliefs and the Multiplicity of Social Norms, Journal of Institutional and Theoretical Economics 168, 280-289

[37] Sherif, M. and C. W. Sherif, 1969, Social Psychology, New York: Harper and Row

[38] Small, A. W., 1905, General Sociology, Chicago, The University of Chicago Press

[39] Tocqueville, A., 1951, Democracy in America, ed. by Phillips Bradley, New York: Knopf [Originally published 1835]

[40] Turner, J. C., 1982, Towards a Cognitive Redefinition of the Social Group, in Tajfel, H. ed. Social Identity and Intergroup Relations, Cambridge: Cambridge University Press

[41] van Damme, E., 1987, Stability and Perfection of Nash Equilibria, Springer-Verlag

[42] Wade, L. L., 1985, Tocqueville and Public Choice, Public Choice 47, 491-508 
Figure 1: Distance $(|z-x|)$ in the Hoteling Model Between the IB (at $z$ ) and an Agent (at $x$ ) Interpreted as Premium Financing Costs $t|z-x|$ Measuring Forgone Expected Risk-

Adjusted Retum

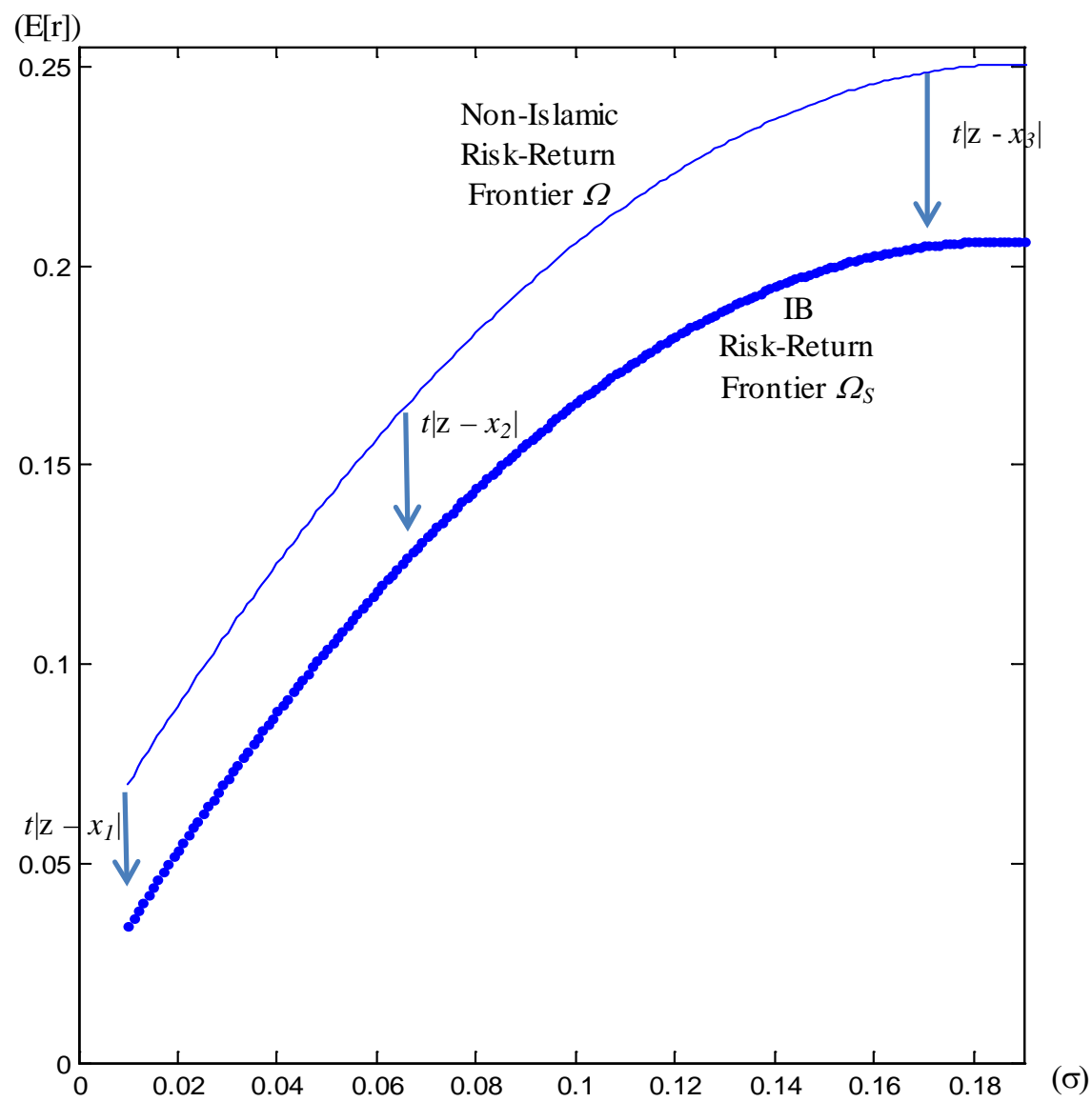


Figure 2: The IB's Optimal Location ( $\left.z^{*}\right)$

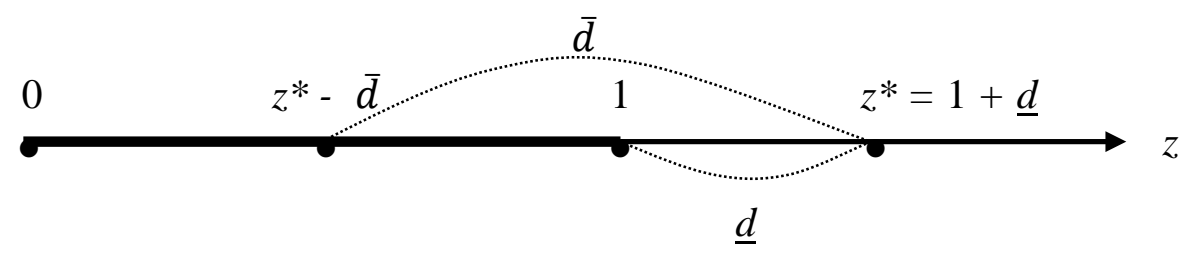


Figure 3: Asymmetric Equilibrium Locations for Two Competing IBs

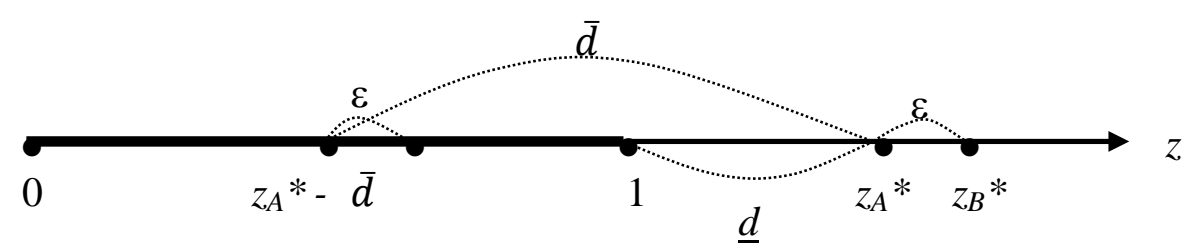

